\title{
Diversidade étnica e fontes orais em fronteiras: vivências e narrativas Camba-Chiquitano entre Brasil e Bolívia
}

\author{
Giovani José da Silva*
}

\section{Considerações iniciais}

Meu primeiro contato pessoal com uma parcela dos índios Kamba ocorreu em novembro de 2005, enquanto finalizava um estudo como consultor do LpT (Programa Luz para Todos), vinculado ao Ministério de Minas e Energia do Brasil. A primeira pessoa a ser procurada no Reduto São Francisco de Assis (local ainda conhecido por muitos regionais como "bugreiro" e designado pelos próprios indígenas como "Alameda"), parte do bairro periférico Cristo Redentor, ao pé de uma morraria próxima à estação rodoviária da cidade sul-mato-grossense de Corumbá (na fronteira com a Bolívia), foi o Sr. Nazário Rocha. Ele havia sido citado inúmeras vezes por Yara Penteado (1980) em sua dissertação de mestrado e conhecê-lo me parecia primordial para o trabalho que desejava desenvolver.

Nazário, liderança reconhecida (e contestada, por alguns) dentro e fora do Reduto, me recebeu de forma amistosa e apresentou-se como possível colaborador da pesquisa, bem como forneceu referências de outros indígenas que poderiam me auxiliar nos trabalhos de desvendamento do passado do grupo. Infelizmente, não foi possível entrevistar outros indígenas além dele.

* Docente da Universidade Federal do Amapá (UNIFAP). Bolsista de Pós-Doutorado Júnior do CNPq e pesquisador colaborador pleno do Departamento de Antropologia da Universidade de Brasília (UnB). 
Não mais na condição de consultor do LpT, em abril de 2006, por ocasião dos primeiros trabalhos de campo, fui novamente recebido pelo velho indígena, que pontuou com muita clareza quais eram seus dele ao falar a respeito dos Kamba.

Suas palavras, em tom calmo e numa mistura de português e espanhol, calaram fundo em minha memória, sendo rabiscadas posteriormente em um caderno de notas. Os Kamba, dizia ele, não queriam mais saber de antropólogos na Alameda, pois estavam cansados de recebê-los, passadas três décadas do primeiro contato, sem qualquer notícia do que fora feito com as informações prestadas. Ainda de acordo com Nazário, os indígenas já tinham fornecido todos os dados à Funai (Fundação Nacional do Îndio), tirado fotografias, respondido a questionários e praticamente nada havia acontecido. Nos últimos anos, porém, perceberam que haviam sido incluídos em alguns programas sociais do governo estadual, mas aguardavam por mais do que isso: que fossem finalmente reconhecidos, de fato e de direito, como indígenas que vivem no Brasil há pouco mais de meio século.

Para Nazário, tudo o que os Kamba queriam era ter contato com alguém que tivesse paciência de ouvi-los. Alguém que soubesse ouvir, escrever e depois divulgar a história dos Kamba, que, na opinião dele, desaparecerão em breve. Isso porque as gerações mais novas sequer se sabem indígenas, já nasceram em ambiente urbanizado, completamente sem perspectivas de se fazerem Camba-Chiquitano num meio hostil a "índios" e "estrangeiros". Desde que vieram os primeiros grupos e se instalaram no Reduto até hoje, é assim que os Kamba se veem tratados por outros: podem até ser considerados "índios" pelos outros, mas são, sobretudo, "bolivianos". Nos meses e anos que se seguiram àquele encontro inicial, pude gravar mais de dez horas de entrevistas com Nazário Rocha e, além delas, realizei encontros com moradores índios e não índios do Cristo Redentor e de outras localidades de Corumbá. As gravações em fitas magnéticas estão sob minha guarda, com cópias disponibilizadas aos Kamba, a pedido dos próprios indígenas.

Decidi, então, a exemplo de Vincent Crapanzano (1980) em Tuhami, realizar um "experimento" (aproveitando a designação do antropólogo) semelhante: a partir das narrativas de uma única pessoa, neste caso, de Nazário, tentar delinear a trajetória histórica, ainda que parcial, de um grupo. Isso porque na falta de pessoas que se dispusessem a falar ou, ainda, na desaparição de outros indígenas que poderiam colaborar como narradores pareceu-me ser essa a melhor saída para escrever a respeito dos Kamba. Percebi que 
em meio a todas as dificuldades que se apresentavam, haveria uma história para contar, marcada por memórias de dor e sofrimento, mas também repletas de esperança e fé. Diferentemente do Tuhami, de Crapanzano, Nazário não foi o único a ser entrevistado, mas, sem dúvida, é a personagem central, o fio condutor de muitas das narrativas coletadas.

O objetivo do artigo é, portanto, apresentar reflexões a partir de narrativas de histórias de vida obtidas ao longo de quatro anos e meio (2006-2009) em trabalhos de campo de curta duração, realizados na fronteira Brasil-Bolívia. Privilegiam-se as narrativas de Nazário Rocha (Nazario Surubi Rojas) por ter sido esse indígena Camba-Chiquitano, inicialmente, o único que se dispôs a falar sobre a presença Kamba em Corumbá. Nesse sentido, as palavras de Roberto Cardoso de Oliveira (1988, p. 100-101; grifo no original), a respeito de quem escreve sobre os outros, mereceram especial atenção:

Elege-se com isso uma sorte de saber negociado, produto de relações dialógicas onde pesquisador e pesquisado articulam ou confrontam seus respectivos horizontes. As interpretações geradas nesse 'encontro etnográfico' - tão bem exemplificadas em Tuhami - obedecem à dinâmica daquilo que os hermeneutas chamam de fusão de horizontes. E o texto que se procura elaborar como resultante desse confronto não pode estar mais submetido a um autor todo soberano, único intérprete de seus dados; mas deve integrar de alguma maneira o saber do Outro e, se possível, ser polifônico, onde as vozes dos Outros tenham a chance de serem ouvidas.

Munido dessa e de outras perspectivas, fui a campo por diversas vezes e confesso não ter conseguido todas as informações que gostaria dos narradores entrevistados. Afinal, quando se trata de fontes orais, "Não se fala, pois, de 'exatidões históricas' ou 'testemunhos de verdades' ou mesmo de 'realidades comprovadas' e sim de visões, construções narrativas, idealizações, que são definidas na exposição dos fatos", uma vez que "a memória falha, erra, desvia, camufla, distorce, inventa. Mas é exatamente isso que interessa” (Meihy; Holanda, 2007, p. 124). Por outro lado, ouso afirmar que com todo esse "experimento" aprendi muito sobre o viver em fronteiras e sobre aqueles a quem o historiador Ronaldo Vainfas (2002) denomina de os "protagonistas anônimos da História”. 


\section{Vozes indígenas em fronteiras}

Em busca de protagonistas da história dos Camba-Chiquitano que pudessem narrar suas memórias, estive por diversas vezes no bairro Cristo Redentor, descrito no texto de Penteado (1980) como uma grande "feira boliviana”. À primeira vista, o Reduto São Francisco de Assis, um núcleo do "Cristo" povoado pelos Kamba, me pareceu semelhante à descrição feita por aquela antropóloga, quando dos seus trabalhos de campo, no final dos anos 1970. A entrada do Reduto, hoje, constitui-se em um corredor de barracos improvisados, feitos de papelão, madeira e de outros materiais precários. Passando-se o corredor, chega-se a uma espécie de "praça central", onde está localizada a casa de Nazário, de alvenaria, em contraste com alguns barracos em volta. Ao longo do tempo da pesquisa, fui percebendo que o "aspecto de favela”, notado por Penteado e também por mim, no início, era apenas aparente: estive, na realidade, dentro de uma aldeia indígena, entendida como uma rede de sociabilidades e vivenciada por aquelas pessoas muito mais em um plano simbólico e cultural do que físico ou puramente espacial.

Foi na casa de alvenaria que Nazário me recebeu para entrevistas previamente agendadas ao longo da pesquisa. Também caminhamos juntos algumas vezes pelo bairro, momentos em que não foi possível gravar as conversas. $\mathrm{O}$ velho Camba-Chiquitano falou do presente e do passado, emocionou-se inúmeras vezes (emocionando-me também), chorou, riu, além de demonstrar uma extraordinária força em relação a todas as adversidades sofridas pelos Kamba, em geral, e particularmente por ele e sua parentela ao longo do tempo. Durante aqueles anos, fiquei horas frente a frente com o homem a quem Penteado assim se referiu em seus trabalhos:

Nazário constitui um exemplo interessante do confronto entre a identidade boliviana e a indígena: como líder [...], era o que mais se empenhava pelo reconhecimento da 'indianidade' do grupo. No entanto, a sua identidade de boliviano mesmo ele negava. A troca de nome (Nazario Surubi Rojas, por Nazário Rocha, mais brasileiro) é um indicador deste escamoteamento. Outrossim, indagado sobre sua naturalidade, respondia-nos: brasileiro, nasci no Paiolzinho, fazenda perto de Cáceres. No que foi desmentido pela sua mãe, Dolores Rojas, que nos afirmou que o mesmo nascera em San Matias, Bolívia. (Penteado, 1980, p. 71). 
Passados trinta anos, aquele indígena outrora jovem e cheio de vitalidade, apesar da idade avançada e do visível cansaço, continuava a afirmar, com muita segurança, que o nome do grupo do qual fazia parte era Kamba, embora sempre tenha ressaltado que no "Cristo" estivesse, em grande maioria, apenas uma parcela do grupo, os Camba-Chiquitano. A respeito do etnônimo Kamba, saliento que, em uma conversa informal com Nazário, ele me perguntou por que os Kadiwéu, Kinikinau e outros grupos tinham seus nomes grafados com a letra $K$. Ainda nessa conversa, foi o próprio Nazário quem deu a ideia de grafar Kamba ( $\operatorname{com} K$ ), assim como se faz com os outros grupos indígenas e Camba-Chiquitano (com $C$ e $C h$, respectivamente), para lembrar a todos do passado do grupo, na Bolívia.

Feito o pedido, decidi uniformizar a escrita do etnônimo (Kamba) e da autodenominação do grupo (Camba-Chiquitano) para fins científicos, em que pese ter publicado alguns trabalhos com variadas nomenclaturas ao longo dos últimos anos em revistas e eventos científicos. Ressalto, porém, que a antropóloga Ruth Henrique da Silva (2009) preferiu utilizar em seu trabalho somente a nomenclatura Camba para denominar todo o grupo. No caso, os indígenas pesquisados por Silva para sua tese de doutorado em antropologia formam um contingente de aproximadamente 400 pessoas, dos quais os Camba-Chiquitano constituem apenas uma pequena parcela, de aproximadamente 50 indivíduos. Assim, prefiro o termo Kamba (respeitando-se as regras da Associação Brasileira de Antropologia) para designar de forma genérica todos os indígenas que habitam Corumbá e região e que procedem da Bolívia e Camba-Chiquitano para a parcela apresentada no presente artigo.

Durante as longas conversas que tivemos, Nazário jamais negou que fosse boliviano de nascimento, explicando-me que as trocas de nome e sobrenome ocorreram quando adquiriu "documentos de brasileiro", o que facilitou o trânsito pela fronteira e a permanência em Corumbá. Nazário teria nascido em 1936, data registrada em seus "documentos de brasileiro", em Corumbá, na época sul do estado de Mato Grosso, atualmente noroeste de Mato Grosso do Sul. De acordo com suas falas, a data está correta, porém, o local de nascimento, na verdade, foi San José de Chiquitos, uma das antigas missões fundadas pelos jesuítas entre os séculos XVII e XVIII no oriente boliviano (e não San Matias, como sua mãe declarara a Penteado, onde teria sido criado na infância). Os pais, Manuel Surubi e Dolores Rojas (sobrenome mais tarde também transformado em Rocha, nos documentos adquiridos no Brasil), eram naturais da Chiquitania, localizada na parte oriental daquele país. Manuel faleceu quando 
Nazário ainda era pequeno; o corpo foi sepultado na Bolívia e, do pai, o filho tem poucas informações e lembranças. Já a mãe veio para o Brasil depois que Nazário se instalou em Corumbá, vindo a falecer, com pouco mais de 80 anos, em meados dos anos 1980. Da infância, nos tempos em que morava em um pueblo, o velho Camba-Chiquitano retém algumas lembranças.

Da família extensa, de oito irmãos, restaram vivos à época da pesquisa apenas Nazário e Casimiro Surubi, atualmente também morador da Alameda. Nazário teve cinco filhos (Roberto, Aparecido, José, um bebê sem nome e Vera), frutos do casamento de Nazário com Julia Surubi, também de origem boliviana (esta sim, natural de San Matias). Os quatro primeiros faleceram ainda na infância; Vera, a única filha sobrevivente, é atualmente casada com um policial civil e tem quatro filhos homens, os únicos netos de Nazário, que é viúvo há muitos anos.

A mãe de Nazário, citada por Penteado inúmeras vezes como grande colaboradora da sua pesquisa de mestrado, falecera muito tempo antes da minha chegada entre os Kamba. Dela, restaram muitas lembranças e, nas memórias do filho, Dolores Rojas (ou Rocha, como preferiu sempre dizer Nazário) aparece como elo entre o passado remoto vivenciado pelo grupo, na Bolívia, e o passado recente, no Brasil. Era Dolores quem dominava a língua dos Chiquitano e a falava fluente e cotidianamente com as pessoas mais velhas da aldeia, relembrando os tempos pretéritos na Chiquitania, em que os Camba-Chiquitano reuniam-se em pueblos y ranchos. Nessa época, na Bolívia, os homens se dedicavam ao fabrico de objetos de palha (chapéus, peneiras etc.), enquanto as mulheres fabricavam cerâmicas (panelas, potes etc.). Tais práticas, contudo, foram rápida e progressivamente abandonadas, quando da chegada dos Kamba ao Brasil.

Em relação ao uso do idioma, Nazário demonstrou não conseguir falar chiquitano, apenas espanhol e português, fluentemente. Segundo suas narrativas, o pai e a mãe falavam chiquitano somente entre si e com as pessoas mais velhas do pueblo; com os filhos, as conversas se realizavam sempre em espanhol, quando ainda moravam na Bolívia, e em português e espanhol, no Brasil. Durante as entrevistas, apresentei uma lista de vocábulos em chiquitano, dos quais quatro foram identificados corretamente por ele: "cavalo" (cabaiursh), "feijão" (kishores), "fogo" (peez) e "peneira" (urupés). A listagem foi obtida por meio dos resultados das pesquisas de Joana A. Fernandes Silva (2001/2002) e meu trabalho consistiu na apresentação, por escrito e por meio da pronúncia, de dezenove palavras recolhidas durante os trabalhos 
de campo realizados pela antropóloga, entre 1998 e 2000, nos municípios mato-grossenses de Cáceres, Porto Esperidião e Vila Bela.

Embora tenha se lembrado de apenas quatro dos dezenove vocábulos apresentados, Nazário afirmou recordar-se de cenas em que ouvia sua mãe conversando com outras anciãs do Reduto, em tempos mais recentes, e também com o pai, quando ainda era pequeno e morava na Bolívia. No presente, a língua é pouco falada pelos Kamba em Mato Grosso do Sul, sendo utilizada somente por alguns mais velhos e, aparentemente, completamente desconhecida pelos mais jovens. Tal situação confirma os resultados das pesquisas da linguista Áurea Cavalcante Santana, ao afirmar que "[...] no Brasil, a situação do [idioma] Chiquitano é preocupante, uma vez que a língua apresenta-se em notável processo de extinção" (Santana, 2008, p. 62).

Ao longo de nossos encontros, as lembranças sobre os "tempos de antigamente" na Bolívia foram permeadas também pelas descrições das "festas de santo", procissões e novenas que marcavam a vida dos Chiquitano. Além disso, o carnavalito, com seus mascarados, foi recordado com certo entusiasmo, embora Nazário, quando criança, juntamente com outros meninos e meninas, fosse impedido de participar de tais atividades, interditadas para os pequenos. Já adulto e vivendo no Brasil, Nazário organizava no Reduto essas festas, nas quais tambores e flautas produziam as músicas que relembravam os sons da Bolívia. O carnaval era organizado pelos próprios indígenas, de acordo com as tradiçôes do grupo, dentro dos limites do bairro. Nazário, quando se referiu ao carnavalito ocorrido no Reduto entre os Camba-Chiquitano, relembrou que:

[...] nós dançávamos [...] batia o bumbo [...] e a flauta [...] tinha a pessoa que tocava, mas hoje não existe mais, já morreu também... [...] Nós saíamos daqui e íamos dançar lá no Cristo. Lá encerrava, lá na lonjura pra cá, dez horas da noite, mas naquela época a gente andava à vontade, hoje a gente não pode [...]. Então agora não pode nem fazer festa [...]. Nós pintávamos de tudo, de chapéu de palha. [...] eu mesmo tinha o meu uniforme, naquela época bem traquejadinho. [...] Nós não tínhamos esse negócio de talco, pegava a farinha de trigo pra jogar porque não tinha como comprar talco. (Rocha, 2006a). ${ }^{1}$

1 O trecho citado, bem como os demais ao longo do texto e que se referem a narrativas indígenas, encontra-se transcrito em tese de doutorado que versa a respeito da presença Kamba na fronteira Brasil-Bolívia (José da Silva, 2009). 
Ainda de acordo com o narrador, as festas no Reduto, ocorridas entre os anos 1970 e 1980, eram organizadas pelos seguintes pasantes (festeiros): Ana, Dolores, Josefa, Mercedes, João, José e Miguel, todos falecidos à época da pesquisa. O "comandante" das festas era o próprio Nazário e o motivo para realizá-las poderia ser um feriado, um domingo ou, ainda, a realização de um batizado ou casamento.

Perguntado sobre o porquê da desaparição das festas na atualidade, especialmente do carnavalito, Nazário informou que, devido a dificuldades financeiras, as famílias não tinham mais recursos para oferecer festejos e que, além disso, pelo fato de haver farta distribuição de bebida alcoólica durante o carnaval entre os índios, muitas vezes, a polícia local, acionada pelos vizinhos, interveio para evitar brigas e confusões. É compreensível que entre os Camba-Chiquitano os recursos financeiros sejam uma preocupação para a realização de quaisquer festejos, uma vez que para os indígenas de origem boliviana, em geral, "uma forma de conseguir o reconhecimento social é a realização de uma festa através dos 'presteríos y pasantazgos', que exigem dos mesmos altas somas de dinheiro. Alguns chegam a endividar-se com empréstimos bancários, ou hipotecando algum bem para realizá-la" (Silva, 1997, p. 70; grifo no original).

Outro motivo para o fim dos festejos pode estar no fato de que muitos deles tinham relação direta com o catolicismo, as chamadas "festas de santo", além das procissões e novenas. Hoje, os Camba-Chiquitano, em grande maioria, abandonaram tais práticas e se converteram a denominações religiosas cristãs pentecostais e neopentecostais, que lhes proíbem, inclusive, o culto às imagens. Creio que por essa razão Nazário tenha falado tão pouco, ao longo das entrevistas e conversas informais, das antigas procissões que percorriam toda a aldeia, indo de casa em casa, com a imagem de Santa Ana, além de outras imagens. ${ }^{2}$

Importante ressaltar que, em espaços públicos, os Kamba participavam de "festas de santo", que na Bolívia tinham/têm um caráter "regional", tais como a da Virgem de Cotoca (padroeira de Santa Cruz de la Sierra) ou a de Nossa Senhora de Orkupiña (padroeira de Cochabamba). Já no Brasil, esses eventos adquiriram um caráter mais "nacional", ou seja, eram festas dedicadas, por exemplo, à Virgem de Copacabana (padroeira do país), que reuniam

2 Cf. Costa (2006) a respeito da devoção católica dos Chiquitano a Santa Ana (nome de uma das misiones fundadas pelos jesuítas) e a outros santos, revelada por meio de procissões e "festas de santo". 
bolivianos de várias procedências, indígenas e não indígenas. Tais festejos podem ser vistos como espaços políticos de recriação de valores culturais e de identidades e, também, como respostas aos processos de estigmatização social enfrentados em conjunto pelos bolivianos, através dos tempos, em Corumbá e por toda a fronteira Brasil-Bolívia.

Sobre a identidade nacional, ao ser perguntado se considerava a si mesmo brasileiro, Nazário afirmou, mais de uma vez, que "[...] a gente não tem o sangue, mas a gente tem um coração brasileiro, a gente já trabalhou, já fez muito nesse Brasil para construir esse país; eu criei meus filhos aqui, estou criando meus netos" ou "[...] a gente, graças a Deus, está aqui como um filho do Brasil, sofreu tanto, trabalhou tanto e continua a trabalhar. Quando for preciso estar pronto para ajudar o nosso Brasil, acho que a gente tem uma vida tranquila, graças a Deus" (Rocha, 2006b). Essas e outras falas revelam os sentimentos ambíguos vividos por esses indígenas, que no passado migraram para o Brasil e até hoje ainda são identificados como "bolivianos" pela população local, reconhecidos, sobretudo, pelo linguajar, que mistura espanhol e português, e pelos traços físicos.

Apesar de terem, em grande maioria, abandonado o catolicismo, os Kamba permaneceram cristãos e se hoje alguns poucos ainda frequentam "festas de santo", talvez seja muito mais pelo sentimento de pertença a uma identidade nacional comum. Entretanto, o passado Chiquitano, ligado aos jesuítas e às práticas religiosas e culturais do catolicismo, foi ressignificado, por exemplo, na escolha do nome do local (dedicado a um santo católico de extrema popularidade, São Francisco de Assis) onde os Kamba vieram a se instalar. O antigo "lixão" da cidade foi, assim, transformado em uma aldeia, criando redes de sociabilidades entre os Kamba de origem Chiquitano, sobretudo da família Surubi. Aliás, Surubi é um sobrenome (apellido) reconhecidamente Chiquitano, tendo sido Pedro Surubi, no passado, um importante médico-sacerdote (cheeserúsch) da região de Koséma (Riester, 1976, p. 154155). Embora não tenha feito menção específica a Pedro, Nazário informou da importância desses homens (há mulheres também em tal função), que se utilizavam, basicamente, de dois métodos curativos: a sucção e a massagem do corpo enfermo.

Ao longo das entrevistas, poucos foram os registros obtidos a respeito dessas práticas curativo-religiosas. Aqui abro um pequeno parêntese para lembrar que algumas das mais preciosas informações fornecidas por Nazário não puderam ser gravadas em fita cassete ou em qualquer outro suporte 
sonoro. Isso porque, embora a convivência e o tempo de cada visita ao Reduto tenham estabelecido uma relação de confiança entre pesquisador e pesquisado (tal como ocorre em trabalhos de campo etnográficos), nem sempre o narrador ou as circunstâncias permitiram a ligação do gravador. É possível dizer, então, que as narrativas coletadas se estruturaram tanto nas gravações em fita cassete como nas anotações no caderno de notas e no diário de campo. Existiram situações em que não havia mesmo como acionar um gravador, pois as narrativas eram feitas espontaneamente e quase como "segredos" que estavam sendo revelados (tive a permissão dos entrevistados para publicá-los). Isso ocorreu, por exemplo, quando Nazário falou sobre os hichi.

Os hichi, de acordo com a narrativa do velho Camba-Chiquitano, seriam seres que tomam conta das águas de rios, riachos e córregos. Não possuem forma definida e não gostam de ser perturbados, embora, em princípio, não sejam hostis. É importante não "mexer" com eles, especialmente em determinadas horas do dia, quando saem para descansar. É nessas horas que se uma pessoa imprudente os perturbar, corre o risco de ser levada para o fundo das águas. A revelação da crença nos hichi (Vera, a filha de Nazário, também confirmou a existência desses seres, embora timidamente) foi um momento dos mais emocionantes na pesquisa, pois tais crenças indígenas tradicionais dos Chiquitano não haviam sido sequer mencionadas durante as entrevistas. A ocultação pode ser fruto da interferência das denominações religiosas cristãs pentecostais e neopentecostais aos quais os Kamba atualmente pertencem. A crença dos Camba-Chiquitano nos hichi também confirma os estudos de Jürgen Riester e o temor demonstrado pelo narrador ao falar a respeito tem suas razões, uma vez que, para os Chiquitano, "El hombre tiene que cuidarse de estos seres y respetar sus propiedades. Si no lo hace, las consecuencias pueden ser enfermedades e inclusive la muerte" (Riester, 1976, p. 150).

Enfim, não posso afirmar que Nazário tenha dito tudo sobre as crenças tradicionais dos indígenas, tais como a dos hichi. Suas narrativas, contudo, expressaram uma rica história de vida, a vivência de um homem que passou uma boa parte dos seus mais de setenta anos lutando pelo reconhecimento de um grupo que, ele crê, desaparecerá após a sua morte. Perguntado, por exemplo, sobre o futuro dos Kamba, Nazário, de forma um tanto pessimista, disse que:

Daqui pra frente, quando acabar, eu não sei não, porque o dia em que eu morrer eles não terão mais ninguém. Se eles podem acabar, eu sei lá; aí não 
tem mais ninguém que vai trabalhar, que vai tomar alguma providência disso. Agora, por enquanto está tudo bom, porque eu sempre estou ao lado deles, às vezes eu falo disso [...]. (Rocha, 2006b).

Sabe-se que Nazário representa, há tempos, uma importante liderança, conhecedora do seu papel entre os indígenas e de como valorizar tal espaço social conquistado, quando ele afirma, por exemplo, ser uma pessoa muito querida por todos e da qual depende a própria continuidade do grupo. $\mathrm{Na}$ opinião dos irmãos Marta e Barnabé, contudo, o fato de muitas pessoas gostarem de Nazário, reconhecendo-o como líder, não teria garantido a visibilidade desejada pelos Kamba entre os não índios da região que escolheram para viver.

Diferentemente de Nazário e de sua parentela, a família de Marta e Barnabé utilizou-se pouco da ferrovia Santa Cruz de la Sierra-Corumbá para realizar a migração para "terras brasileiras”. A mãe, Petrona Lopes (Petrona Surubi), empregada doméstica, era natural de San José de Chiquitos, e o pai, Antônio Soares Arteaga (Antonio Suárez Arteaga), pescador, nasceu em Puerto Suárez, município boliviano, próximo a Corumbá. Ambos, já falecidos, vieram casados da Bolívia, entre os anos de 1954 e 1955, e tiveram sete filhos: Paulo, Silas, Ana, Dalila, Marta, Ester e Barnabé. Dona Petrona era indígena Chiquitano e sempre falou com orgulho para os filhos sobre suas origens, enquanto o pai era indígena da fronteira, de etnia indefinida pelos filhos. Só foi possível entrevistar estes dois narradores já no final dos trabalhos de campo, quando consentiram em gravar uma narrativa e autorizaram sua divulgação.

Marta Mafalda Lopes Arteaga de Oliveira, empregada doméstica, nascida em 1961, em Corumbá, é casada com um não indígena brasileiro, de origem nordestina, e tem uma filha. Seu irmão, Barnabé Arteaga Lopes, pintor de letreiros, nascido em 1954, em Puerto Suárez, é casado com Lucinda Surubi Arteaga (do mesmo sib - ou parentela de consanguíneos e afins - do Sr. Nazário, embora não seja parente sanguíneo) e o casal tem sete filhos. Marta e Barnabé estão hoje no Reduto, onde vivem há mais de trinta anos, tendo passado a infância às margens do rio Paraguai. A grande enchente de 1974 teria provocado a mudança dos Arteaga para o bairro Cristo Redentor, junto aos outros Kamba, segundo as narrativas dos irmãos. Nessa época, o Reduto era conhecido como "bugreiro", pois, nas palavras de Barnabé, "[...] aqui havia mais índio Camba do que propriamente brasileiro" (Oliveira; 
Lopes, 2008). Quando falaram a respeito da própria identidade indígena, os irmãos salientaram que se reconhecem como Kamba e não exatamente como Chiquitano, por conta de o pai não ser da Chiquitania.

Das muitas lembranças do passado vivido no Reduto, as festas de carnaval (carnavalito) foram entusiasticamente recordadas, especialmente a presença dos mascarados (mascaritos):

Saíam as festas de carnaval, brincavam entre eles, era uma alegria só entre eles mesmos! [...] quando a gente via, eles se reuniam, se enfeitavam, pintavam o rosto de carvão e saíam de casa em casa e quem passava por perto se sujava tudo... [...] no Brasil [o carnaval] não é igual [...] o de lá [...]. Tinha [mascarados]. (Oliveira; Lopes, 2008).

Embora não sejam católicos nos dias atuais, os irmãos Arteaga recordaram inúmeras "festas de santo" realizadas no passado no "Reduto", destacando as de São João e de Santa Isabel. Antes de se tornar evangélica, Petrona fora, durante muitos anos, uma católica fervorosa. A indígena falava somente português e espanhol com os filhos, conversando em Chiquitano apenas com as pessoas mais velhas da aldeia. Aos filhos, nascidos no Brasil ou na Bolívia, Petrona fez questão de ensinar apenas a Língua Portuguesa. Recentemente, foi localizado um tio materno dos narradores, João, vivendo do lado brasileiro da fronteira Brasil-Bolívia (fora do Reduto), falante do idioma indígena. Infelizmente, não foi possível entrevistar esse senhor.

A medicina tradicional dos Chiquitano foi aprendida pela mãe de Barnabé e Marta nos tempos em que ainda morava na Bolívia:

Minha mãe dizia que ela morava com o pai, retirado da cidade, e o pai dela entendia muito de medicina caseira, conhecia muitas plantas medicinais. Quando tinha, por exemplo, picada de cobra, ele corria e arrancava aquela planta [...], ele mastigava e combatia [o veneno] com a própria raiz. (Oliveira; Lopes, 2008).

Marta, por sua vez, lembrou com emoção as palavras da mãe sobre a infância, vivida na Chiquitania, que ela fazia questão de relatar aos filhos e netos: 
Ela lembrava muito da infância, falava muito da infância, que ela foi muito feliz, muito feliz mesmo. Lembrava quando o pai saía para caçar, trazia as caças, limpava, depois comia. Daí ele voltava, ficava dois, três meses e lá vinha com caça... Ela lembra[va] que ela comia muito milho assado, mandioca assada. [Ela dizia:] 'Eu não fui criada com este negócio de arroz, feijão e bife! Minha comida era milho fermentado, peixe frito, frango caseiro.... Por isso, então, eu creio que isso deu muita força para ela. (Oliveira; Lopes, 2008).

Apesar da infância recordada como um período feliz, Petrona afirmava aos filhos que durante sua adolescência, a situação na Bolívia, especialmente para os indígenas, tornou-se muito difícil, o que a obrigou a fugir, perdendo-se dos irmãos e dos pais. Ao fazer as contas sobre a idade de Petrona, os irmãos Marta e Barnabé afirmaram que a mãe falecera com 73 ou 74 anos, em 2007, tendo nascido, pois, por volta de 1933. Quando da fuga para a fronteira com o Brasil, em 1946, a mãe dos narradores estaria com treze ou catorze anos.

Petrona mantinha boas relações de amizade e vizinhança com Nazário, embora não fossem parentes sanguíneos. Ao longo da entrevista, os irmãos Arteaga revelaram que o sobrenome (apellido) da mãe era, na verdade, Surubi! O sobrenome Lopes fora “arranjado", quando o grupo familiar obteve registros de nascimento no Brasil, em Ladário, município brasileiro próximo a Corumbá. "Naquela época”, revelou Barnabé, "1950 e 1960, por aí, não aceitavam o sobrenome boliviano Surubi” (Oliveira; Lopes, 2008). Dessa forma, imagina-se que Petrona pertencesse ao mesmo sib de Nazário e que a aproximação de ambos, após a enchente de 1974, se deu, também, por laços de identidade étnica, com a chegada da família ao Reduto e a permanência dos filhos, até os dias de hoje, na aldeia.

Embora houvesse forte aproximação dos Arteaga com os Surubi, Barnabé e Marta revelaram-se descontentes com a atuação de Nazário como liderança indígena Kamba:

[...] o Nazário, como pessoa, é um excelente amigo, companheiro, mas em se tratando [de liderança] [...], ele tinha acesso às pessoas certas para trazer ajuda para nós, [...] ele nunca deu muita importância, nunca levou isso pra frente. [...] uma reclamação que eu faço é que ele poderia fazer muita coisa por nós aqui. 
Ele chegou até ir para Brasília, [...] mas a gente nunca soube de nada. Ele nunca foi de chegar e dizer que aconteceu isso, eu fui resolver isso... A gente ficou esperando que ele tomasse uma atitude, que fizesse alguma coisa. (Oliveira; Lopes, 2008).

O que parece ter ocorrido, efetivamente, é que as frustradas tentativas de Nazário de se fazer visto e reconhecido como indígena Kamba no Brasil, (bem como todo grupo Camba-Chiquitano morador do Reduto), redundaram na desconfiança, por parte de alguns, do seu papel como líder. Por outro lado, os preconceitos alimentados pela população regional em relação aos bolivianos, sobretudo os de origem indígena, tais como os Chiquitano, tornaram tal parcela da população praticamente "invisível” aos olhos dos não indígenas, inclusive dos moradores do próprio Cristo Redentor.

\section{Possíveis diálogos entre história oral e antropologia}

Para contar uma história ou as histórias (e não "a história”) daqueles que hoje se autodenominam Camba-Chiquitano e que são conhecidos na região do município sul-mato-grossense de Corumbá apenas como Kamba, dentre outras denominações, creio ter sido necessário refletir sobre as imbricações entre história e antropologia e as possíveis relações dessas áreas do conhecimento com as fontes orais. Para trabalhar com populações indígenas, seja no Brasil, na Bolívia (de onde os Kamba mais velhos são oriundos) ou em qualquer outro lugar, especialmente em fronteiras (físicas e/ou simbólicas), exige-se certo treinamento dos ofícios etnográfico e etnológico. Não por acaso, as fontes orais constituíram privilegiado (mas não exclusivo) recurso metodológico na pesquisa, na medida em que se verificou, também, uma enorme escassez de informações escritas (ou registradas em quaisquer outros meios) sobre esse grupo, localizado atualmente em fronteiras políticas de Estados nacionais.

Sem se pretender uma rígida delimitação de fronteiras disciplinares, verifica-se que nos espaços limítrofes ocorrem deslocamentos que podem tornar fluidas essas mesmas fronteiras. Os diálogos entre história e antropologia, importantes e salutares para o desenvolvimento de ambas as áreas do conhecimento e, especialmente, para as pesquisas em história indígena, têm-se mostrado um fértil terreno de debates e trocas de experiências, seja no Brasil ou 
em outras partes do mundo (Silva; José da Silva, 2010). História e antropologia têm, portanto, muito a dialogar quando os temas em debate são culturas, mitos, identidades, fronteiras, comunidades étnicas etc. Refletir sobre essas imbricações auxilia os pesquisadores que se aventuram pelos (às vezes movediços) terrenos da história indígena. $\mathrm{O}$ interesse por temas ainda considerados "exóticos" (festas, mitos etc.) e mesmo o ingresso no "campo das identidades" não são vistos com bons olhos por uma parte da comunidade acadêmica de historiadores. Diga-se de passagem, pelo menos no Brasil, os antropólogos parecem aceitar muito mais tranquilamente o diálogo com a história do que o contrário. A aproximação não ocorre, pois, sem dificuldades ou atritos.

Os debates a respeito da distinção entre o uso de fontes orais por parte de historiadores e de cientistas sociais (antropólogos, sociólogos e cientistas políticos), ainda que escassos, não são novos no país. Em um pioneiro texto, publicado pela primeira vez em 1986, Guita Grin Debert (2004) já levantava problemas relativos à utilização da história de vida e à oralidade, mostrando uma possível aproximação teórico-metodológica da antropologia com a problemática das fontes orais. De acordo com Debert, histórias de vida e relatos orais fazem convites irrecusáveis para se reverem interpretações de certa forma já consagradas, desenvolver novas hipóteses e encaminhar pesquisas de forma a refinar conceitos explicativos e seus pressupostos. A autora chama a atenção, inclusive, para a ideia de que a memória exige a atenção do pesquisador não tanto para o passado, mas, sobretudo, para a problemática relação passado/presente. O empreendimento, levado a cabo por sociólogos e historiadores, de produzir novos documentos através da história oral é incontestavelmente rico e importante, na medida em que se tem em vista o presente ou se considera que o usuário potencial desse material está localizado no futuro.

Assim, um documento produzido pela metodologia da história oral, antes de reconstituir ou mostrar fatos do passado, possibilita perceber que as fontes orais constituem-se em armas na luta contra outras interpretações históricas que podem estar vigorando hegemonicamente no presente, as chamadas "versões oficiais". Essas fontes podem retirar, pois, das condições de marginalidade e subalternidade, indivíduos e grupos que passam a ver e sentir suas histórias escutadas, respeitadas e, mais do que isso, preservadas. Desse modo, a história indígena pode se beneficiar muito de tal metodologia, uma vez que vozes até então ignoradas e geralmente condenadas ao esquecimento passam a ser ouvidas, registradas, analisadas e disponibilizadas, inclusive para os próprios sujeitos das pesquisas. 
Outro importante texto é o de Elina Pessanha (1996), publicado na coletânea (Re)introduzindo história oral no Brasil, organizada por José Carlos S. B. Meihy. O texto discute o uso da história oral e as fronteiras disciplinares, debruçando-se sobre três trabalhos, numa perspectiva comparativa. O objetivo da autora é refletir sobre encontros e diálogos, "via história oral", entre ciências sociais e história. Pessanha afirma que tais momentos têm se dado mais frequentemente em torno de temáticas comuns do que sobre problemas de ordem teórica e metodológica. Ao comparar trabalhos do antropólogo José Sérgio L. Lopes, da historiadora Angela M. de Castro Gomes e da socióloga Wilma Mangabeira, a autora constata a presença marcante de fronteiras entre as disciplinas - antropologia, história e sociologia - em que pese o movimento de diálogo entre as mesmas e as eventuais proximidades teóricas evidenciadas. Pessanha se refere, ainda,

[...] à necessidade de ao invés de apressadamente tomá-las como superadas - clarear essas fronteiras disciplinares. Admitir a existência desses distintos "territórios", reconhecer a importância de suas tradições e dos conflitos internos que informaram e informam as suas configurações, pode e deve lançar luz às futuras colaborações, inclusive no que tange ao uso da História Oral. Creio que só assim se formarão pontes verdadeiramente sólidas entre nós. (Pessanha, 1996, p. 81).

A autora observa que, nas ciências sociais, o uso das informações obtidas por meio das narrativas (designadas por Pessanha como "depoimentos") é fundamental para elaboração das análises. ${ }^{3}$ Assim, as entrevistas são usadas de forma fragmentada para tipificar ou ilustrar acontecimentos ou, ainda, como material a ser efetivamente analisado em seu conteúdo pelos pesquisadores, de forma a apoiar a reflexão empreendida. A história, por sua vez, produz registros que servem à análise, mas que também são devidamente pensados como material a ser utilizado por outros pesquisadores. Dessa forma, em história indígena é possível pensar, diante da perspectiva apontada por Pessanha, na identificação mais rigorosa das entrevistas e na maior explicitação das características dos colaboradores, de forma que as narrativas possam servir a

3 Ressalva-se que, atualmente, tem se evitado termos tais como "depoentes", "depoimentos", "testemunhas" ou, ainda, "informantes", que remetem a uma linguagem jurídica e fazem parecer o trabalho do historiador similar ao de um investigador policial inquirindo pessoas. 
outros interessados que, ao acessá-las posteriormente, retirem delas informações substantivas para novas e enriquecedoras análises.

Tais pesquisas vêm recebendo sugestivas contribuições nos últimos anos, com destaque para as de Alessandro Portelli, que desenvolve importantes reflexões de cunho teórico sobre a produção de fontes orais. Portelli, um dos expoentes da história oral, aborda a questão do uso que delas fazem historiadores e antropólogos, por exemplo, a partir de pesquisas sobre um evento denominado "o massacre de Civitella Val di Chiana”, ocorrido em 1944, na Itália. Com base nos trabalhos apresentados na conferência internacional In memorian: por uma memória européia dos crimes nazistas após ofim da Guerra Fria, ocorrido em Arezzo, em 1994, Portelli desenvolve instigantes reflexões. Dentre os autores que se apresentaram na referida conferência e que mereceram a atenção do historiador estava o pesquisador italiano Pietro Clemente, para quem o antropólogo, diferentemente do historiador, "está mais interessado 'nas representações de uma comunidade do que na verdade dos fatos ou na tendência dos valores" (Portelli, 2002, p. 107). Portelli concorda com a distinção de Clemente entre os "fatos" do historiador e as "representações" do antropólogo, mas ressalva que apenas considerando-as em conjunto é que se pode distinguir uma da outra, já que:

Representações e 'fatos' não existem em esferas isoladas. As representações se utilizam dos fatos e alegam que são fatos; os fatos são reconhecidos e organizados de acordo com as representações; tanto fatos quanto representações convergem na subjetividade dos seres humanos e são envoltos em sua linguagem. Talvez essa interação seja o campo específico da história oral, que é contabilizada como história com fatos reconstruídos, mas também aprende, em sua prática de trabalho dialógico e na confrontação crítica com a alteridade dos narradores, a entender representações. (Portelli, 2002, p. 111; grifo no original).

Portelli dá um importante passo além da mera constatação de que o passado, relatado nas narrativas orais, é uma construção da memória - realizada no tempo presente -, sublinhando a necessidade de se tomarem os "fatos" do historiador e as "representações" do antropólogo em conjunto, para o desvendamento dessa construção, conforme já observou Verena Alberti (2004, p. 41). Acredito que a "interação" proposta por Portelli e outros historiadores 
que refletem sobre o uso das fontes orais possa ser tentada, com relativo sucesso, em trabalhos de história indígena.

A divulgação dos resultados de pesquisas envolvendo populações indígenas e fontes orais, até o momento, é muito escassa no Brasil, diferentemente do que ocorre em outros países das Américas, tais como a Bolívia (cf. Riester, 1994; Hagen, 1992, por exemplo). E apesar da incipiente produção, os especialistas brasileiros no assunto já apontam para convergências com o que se tem produzido no exterior. Assim, tanto estudiosos nacionais como estrangeiros concordam que, nas pesquisas historiográficas realizadas com fontes orais sobre populações indígenas, emergem como relevantes certos cuidados metodológicos na leitura e na interpretação das narrativas coletadas e registradas, que remetem, principalmente, às problemáticas das culturas e das relações historiador/colaborador, sociedade indígena/sociedade não indígena.

Edinaldo Bezerra de Freitas (2004, p. 187) afirma que, nessas condições, “Fazer História oral é dar voz e dialogar com 'o outro'. Fazer História oral indígena, então, é realizar esta tarefa de maneira mais profunda possível, pois se trata de contatar 'o outro' no sentido pleno da conceituação cultural'. Mais do que "dar voz", contudo, a história oral com populações indígenas permite aos pesquisadores que se ouça e veja o outro, tentando compreender a sua lógica própria, situada em contextos culturais diversos. Pode-se dizer, então, que o historiador deve "dar ouvidos" ao que o outro fala, abandonando, assim, uma postura autoritária de tentar ser o porta-voz de quem quer que seja. Essa ideia se fez presente nesta pesquisa já no primeiro encontro dialógico, quando Nazário me revelou que gostaria de saber se eu teria paciência para ouvi-lo.

A metodologia da história oral - que observa cuidados de como coletar informações, entrevistar, confrontar versões etc. - não pode ser, pois, confundida com o empreendimento etnográfico, embora ambos possam alimentar uma mesma pesquisa. A rigor, a chamada história oral é apenas "uma parte do conjunto de fontes orais e sua manifestação mais conhecida é a entrevista” (Meihy; Holanda, 2007, p. 14). As entrevistas, por sua vez, geram sempre pelo menos um documento material, que é a gravação. Grande parte dos projetos de história oral implica a elaboração de um texto escrito, derivado das entrevistas, sendo primordial que se pense tanto no destino das gravações, que devem ser mantidas e disponibilizadas a um público amplo, além dos sujeitos pesquisados, como no destino do próprio texto escrito. Os trabalhos de pesquisadores da história indígena, em constante diálogo com a 
antropologia e outras áreas do conhecimento (linguística, arqueologia etc.), podem ser caracterizados como verdadeiras "práticas de fronteira".

Para Lilia K. M. Schwarcz (2000, p. 11), tais práticas

[...] podem ser marcadas por "relações de boa vizinhança", na feliz expressão de Robert Darnton, em O beijo de Lamourette (1990), mas também, e com freqüência, são palco de litígio. $\mathrm{O}$ espaço para a verificação de limites e para a demarcação de parte a parte nem sempre é objeto de consenso. $\mathrm{Na}$ delimitação da divisão de áreas, assim como na separação de disciplinas e de objetos, os critérios diferem, as justificativas são sempre múltiplas, assim como é nesse lugar que se estabelece o jogo da alteridade.

Mais do que uma arena "de litígio", essa fluida área de fronteiras disciplinares pode ser também palco de "relaçóes diplomáticas". Se os antropólogos têm muito a colaborar com os historiadores, seja por meio da metodologia do trabalho de campo ou da reflexão sobre conceitos tais como culturas e identidades, é inegável que a história também pode dar sua contribuição ao estudo de grupos étnicos, em uma perspectiva diacrônica. Afinal,

La integración de culturas tribales en formaciones estatales nacionales, la asimilación de lenguas coloniales, la experiencia de las misiones, el surgimiento de asociaciones colectivas y la aparición de la fuerza de trabajo individual, la integración en contextos económicos extraños, el éxodo hacia las ciudades, la usurpación de tierras y la experiencia de la dominación extranjera, son algunos de los factores que hoy ya no pueden ser ignorados por los antropólogos contemporáneos, cuando se trata de describir a grupos étnicos [...]. (Hagen, 1992, p. 104; grifo no original).

Os fatores levantados por Ulrike Hagen permitem entrever a necessidade de os pesquisadores da história indígena, além dos antropólogos, estarem atentos para as profundas transformações que têm afetado os grupos étnicos em todo o mundo, especialmente nos últimos séculos. Ao se compararem os trabalhos de historiadores e antropólogos envolvidos com pesquisas em que se utilizam fontes orais, podem-se distinguir algumas afinidades e outras tantas diferenças a respeito de como cada grupo de profissionais aborda os sujeitos. Sobre as afinidades, percebe-se que, em se tratando de períodos próximos do presente, os grupos pesquisados pela antropologia e pela história 
geralmente configuram-se como marginalizados dentro dos Estados nacionais. Nessa situação, fontes escritas a respeito deles não existem ou não estão disponíveis de forma satisfatória, o que também valida, de certa forma, as narrativas orais como fontes cientificamente aceitáveis. Os estudiosos confiam no conhecimento cotidiano, coletado graças à sua presença permanente (no caso da antropologia) ou mediante entrevistas (no caso da história oral). As fontes orais assim obtidas são transcritas, a fim de ser aproveitadas, além de armazenadas.

Ainda que se possa dizer que existe uma situação muito semelhante entre o trabalho do antropólogo que vai a campo e formula perguntas e um pesquisador de história oral ao realizar entrevistas, salienta-se que são diferentes os conteúdos que cada um quer obter com suas indagações. Enquanto antropólogos tratam de captar certos componentes da vida cotidiana como dados etnográficos ou entendem a si mesmos como ouvintes de uma tradição oral e coletiva, a história oral esforça-se por captar, por intermédio da colaboração de narradores, biografias individuais. Essas biografias devem refletir, de forma coerente, a experiência subjetiva de indivíduos no transcurso de suas vidas. Assim, "los contenidos de la tradición oral [captados por antropólogos] tienen un alcance temporal en el pasado mucho mayor que la perspectiva histórica de la Historia Oral, limitada al tiempo de vida del respectivo informante" (Hagen, 1992, p. 108; grifo no original).

O material que surge da situação de encontro entre indivíduos, dos quais uns abandonam temporalmente suas atividades cotidianas para buscar o outro, possui características distintas para a antropologia e a história. No trabalho de campo etnográfico, esse encontro tem, em geral, uma duração mais longa do que aquela que ocorre com as entrevistas em história oral. Outros aspectos diferenciadores: a transcrição no trabalho antropológico, em geral, é menos exata, mais incompleta; na apresentação do material, a individualidade dos narradores é preterida em favor da expressão geral de uma coletividade. Em outras palavras, para muitos antropólogos, não é "um determinado" Kamba quem fala, mas os próprios Kamba, por meio da fala de um indivíduo (geralmente mais velho ou de relevância para o grupo). As entrevistas de história oral sustentam-se na força individual de expressão de uma ou mais pessoas, cujos nomes devem ser sempre citados (salvo casos excepcionais) como narradores ou colaboradores.

Finalmente, e não menos importante, 
En cuanto al trabajo práctico debe designar-se la diferencia que radica en el hecho de que la Historia Oral realiza el proceso concreto de la transcripción de una manera a menudo más exacta y cuidadosa que lo que suele ocurrir en las transcripciones antropológicas de textos. (Hagen, 1992, p. 109; grifo no original).

Antropólogos e historiadores têm muito a dialogar, portanto, quando o assunto é o estudo de populações indígenas e suas tortuosas trajetórias espaciais e temporais no atual território brasileiro e, em perspectiva mais ampla, latino-americano, pois o avanço nas técnicas de pesquisa, o amadurecimento das reflexões teóricas, a problematização da vocação das ciências em geral, que de certa forma sempre estiveram voltadas para as elites e para uma "versão oficial” da história, abrem possibilidades para a descoberta do outro, nem sempre tão distante do eu, como afirma José de Souza Martins (1997). Apesar do incremento no interesse pela história de populações indígenas, há muito ainda a ser pesquisado, analisado, debatido e divulgado.

Num âmbito de aproximadamente 240 sociedades indígenas no Brasil (Ricardo; Ricardo, 2011), chega-se à conclusão de que pouco se conhece sobre as especificidades históricas desses grupos e ainda há uma longa caminhada até que se possa dizer que há um bom domínio da historiografia e mesmo da etnografia referente à temática. Pode-se compreender a importância desses estudos levando-se em conta que a história do Brasil e a história das populações indígenas são intimamente entrelaçadas e o desafio continua grande, pois ainda "persiste um abismo entre a produção acadêmica e as percepções indígenas de seu papel na história do Brasil” (Monteiro, 1999, p. 248).

\section{Considerações finais}

Finalizando, ressalto ter sido muito proveitosa a perspectiva diacrônica na compreensão da situação atual dos Kamba, mas reafirmo que as "práticas de fronteira" interdisciplinares foram importantes, inclusive para pensar a presença desses indivíduos nas fronteiras dos territórios brasileiro e boliviano. Aqui o conceito de fronteira, também emprestado da sociologia e da antropologia, foi pensado como "um dos mais desafiantes cenários de investigação sobre a relação dialética entre identidade étnica e identidade nacional" (Cardoso de Oliveira, 2006, p. 101). E evidentemente não se tratou, 
seguindo os conselhos de Cardoso de Oliveira, de realizar uma pesquisa a respeito "de fronteiras", mas apenas elaborá-la "na fronteira", neste caso específico de Brasil e Bolívia. ${ }^{4}$ Uma pesquisa em história indígena na fronteira de dois países sul-americanos e em fronteiras disciplinares constitui-se em grande desafio. Espero ter conseguido, ao menos, desvendar parte do processo histórico que engendrou as identidades étnicas e nacionais dos Kamba em "um espaço marcado pela ambigüidade das identidades - um espaço que por sua própria natureza, abre-se à manipulação pelas etnias e nacionalidades em conjunção" (Cardoso de Oliveira, 2006, p. 108).

A situação vivida nas condições de fronteira, qual seja a de indivíduos que vivem compulsoriamente em contato com o outro, que se encontra sob outras leis, fala outras línguas, possui outros costumes e padrões culturais, pôde, assim, ser recuperada historicamente, sem perder de vista que:

En casi toda América Latina, las fronteras son áreas de ocupación relativamente reciente y en las que las hegemonías estatales se ejercen con poca eficiencia salvo a nivel militar. Por otra parte son también el lugar de arrinconamiento de numerosos pueblos indígenas, ya que las expansiones de los estados surgidos en el siglo XIX se realizaron desde áreas centrales, lo que convirtió a las fronteras en zonas marginales a la presencia estatal. (Bartolomé, 2003, p. 60).

A marginalidade a que se refere Miguel Alberto Bartolomé no trecho citado acima, em suas dimensões econômica, política e sociocultural é um importante elemento na maioria dos contextos de investigação dos grupos étnicos que vivem em fronteiras. Homens e mulheres Kamba constituíram-se como "indivíduos fronteiriços", na medida em que ora se fizeram ver como índios, ora como não índios, além de contextualizarem continuamente suas próprias identidades nacionais, fazendo-se passar por brasileiros e/ou bolivianos. A condição de "indivíduos à margem" - cujos sinais diacríticos, ou seja, os sinais da diferença, embora não tenham desaparecido, tornaram-se

4 Assim, recorro à instigante ideia de que os antropólogos (e os historiadores que realizam trabalho de campo) não estudam "as" aldeias, mas "nas" aldeias (Geertz, 1989). De acordo com Cardoso de Oliveira (2006, p. 101; grifo no original), “[...] não se trata de realizar pesquisas a respeito de fronteiras, mas apenas realizá-las na fronteira". 
tênues, a ponto de serem considerados por muitos como "extintos" - marca a situação-limite vivida por esses indígenas há décadas.

Segundo Hagen:

En el momento, en el que las características de etnicidad y cultura distintiva de un grupo observado pierden importancia, como condición necesaria para una investigación antropológica, el concepto más general de marginalidad obtiene prioridad, y ese concepto es hoy compartido por la antropología y por la Historia Oral, cuando se trata de caracterizar el objeto de su investigación. (Hagen, 1992, p. 106; grifo no original).

Uma das questões norteadoras foi, pois, perceber que esses indígenas, ao longo de suas trajetórias, não desejaram ser “índios do Brasil”, mas apenas reconhecidos como Camba-Chiquitano "no Brasil" ou em qualquer outro lugar. As narrativas orais apontam para uma vida de muitas dificuldades na Bolívia, que os teria obrigado a buscarem um lugar melhor para viver e se reproduzirem física e culturalmente, mesmo que a vida no novo país também oferecesse vicissitudes.

Os Kamba não desejam que suas trajetórias sejam esquecidas ou jogadas no lixo (numa alusão ao fato de que houve tempo em que os próprios índios se sentiam "jogados no lixão da cidade de Corumbá”). Quando se fala no plural, "os Kamba”, não se está, absolutamente, tomando as palavras de Nazário como as únicas palavras representativas de todo um grupo. A trajetória individual de Nazário revelou aspectos que podem ser estendidos aos Camba-Chiquitano localizados atualmente no Reduto, pois foi esse senhor indígena quem iniciou o movimento migratório para Corumbá, no início da década de 1950. Depois dele foram sendo chamadas outras famílias indígenas de sua parentela para viverem do lado brasileiro da fronteira, criando a localidade hoje conhecida como Alameda São Francisco de Assis e ainda referida por alguns moradores locais não indígenas como "bugreiro".

Ressalto que os Kamba surgiram “índios no Brasil” em um cenário francamente desfavorável, em que a Funai procurava, no final dos anos 1970, estabelecer critérios que definiriam quais seriam ou não os índios e as comunidades indígenas do país, além de especificar as condições necessárias para a emancipação dos mesmos. Tal processo culminaria com a alteração no Estatuto do Índio (Carneiro da Cunha, 1986, p. 109-112), o que de fato não ocorreu por conta da mobilização de indígenas, indigenistas e antropólogos. 
Ainda assim, a Funai não estendeu aos Kamba as garantias de assistência do órgão tutor, entendendo-os como índios "estrangeiros" e, portanto, fora da esfera de proteção e apoio.

Pode-se afirmar que este trabalho encontra-se em fronteiras disciplinares, entre a história e as ciências sociais, notadamente a antropologia. Afinal, se não fiz longos trabalhos de campo, como requer o ofício etnográfico, arrisquei-me a lançar um olhar antropológico sobre as (poucas) fontes que encontrei ao longo do caminhar da pesquisa. Por outro lado, intentei dar uma visão diacrônica dos Kamba, não me preocupando com o "presente etnográfico" e, tampouco, em inventariar, por meio das narrativas orais, costumes, tradiçóes e modos de viver em (des)uso. Confesso, entretanto, ser essa posição (a de um aprendiz de historiador tentando fazer, em certos momentos, o papel de antropólogo) um tanto incômoda, embora rica em experiências e possibilidades. Nessa perspectiva, considero-me, em tempos globalizados, também um pesquisador "na fronteira".

No caso dos Kamba, o que se fez aqui foi a elaboração de histórias de vida, a partir de memórias indígenas, revelando parte da história dos Kamba, hoje moradores de Corumbá, por conta das próprias circunstâncias que marcaram os trabalhos de campo entre aqueles indígenas e a escassa massa documental a respeito do grupo, tanto no Brasil como na Bolívia. As vozes indígenas encontradas em "situações de fronteiras" permitiram entrever, graças aos aportes teórico-metodológicos da história oral e da antropologia, os indígenas Kamba não mais como "vítimas" e sim como agentes de sua própria história. Eles desejam contar essa história, tentando, de certa forma, controlar o passado do grupo e imaginando um futuro mais auspicioso, ainda que incerto. Conclui-se que tal situação remete àquela mais geral das populações, indígenas e não indígenas, que vivem em condições de marginalidade na América Latina em tempos atuais.

\section{Referências}

ALBERTI, V. Owvir, contar: textos em história oral. Rio de Janeiro: FGV, 2004. 196 p.

BARTOLOMÉ, M. A. Movimientos indios y fronteras en America Latina. In: SCOTT, P.; ZARUR, G. (Org.). Identidade, fragmentação e diversidade na América Latina. Recife: UFPE, 2003. p. 49-65. 
CARDOSO DE OLIVEIRA, R. Caminhos da identidade: ensaios sobre etnicidade e multiculturalismo. São Paulo: Unesp; Brasília: Paralelo 15, 2006. 258 p.

. Sobre o pensamento antropológico. Rio de Janeiro: Tempo Brasileiro; Brasília: CNPq, 1988. $201 \mathrm{p}$.

CARNEIRO DA CUNHA, M. Antropologia do Brasil: mito, história, etnicidade. São Paulo: Brasiliense, 1986. 173 p.

COSTA, J. E. F. M. da. A coroa do mundo: religião, território e territorialidade Chiquitano. Cuiabá: EdUFMT, 2006.223 p.

CRAPANZANO, V. Tuhami: portrait of a Moroccan. Chicago: The University of Chicago Press, 1980. $187 \mathrm{p}$.

DEBERT, G. G. Problemas relativos à utilização da história de vida e história oral. In: CARDOSO, R. C. L. (Org.). A aventura antropológica: teoria e pesquisa. 4. ed. Rio de Janeiro: Paz e Terra, 2004. p. 141-156.

FREITAS, E. B. de. Fala de índio, história do Brasil: o desafio da etno-história indígena. História Oral, São Paulo, n. 7, p. 181-197, jun. 2004.

GEERTZ, C. A interpretação das culturas. Rio de Janeiro: LTC, 1989. 213 p. (Antropologia Social).

HAGEN, U. História oral indígena. Trad. Oscar Zambrano. Santa Cruz de la Sierra: APCOB, 1992. 243 p. (Pueblos indígenas de las tierras bajas de Bolivia, 4).

JOSÉ DA SILVA, G. A presença Kamba na fronteira Brasil-Bolivia (1938-1987): identidades, migrações e práticas culturais. 291 p. Tese (Doutorado em História) - UFG, Goiânia, GO, 2009. 2012. $237 \mathrm{p}$.

MARTINS, J. de S. Fronteira: a degradação do outro nos confins do humano. São Paulo: Hucitec, $1997.213 \mathrm{p}$.

MEIHY, J. C. S. B.; HOLANDA, F. História oral: como fazer, como pensar. São Paulo: Contexto, 2007. 175 p.

MONTEIRO, J. M. Armas e armadilhas: história e resistência dos índios. In: NOVAES, A. (Org.). A outra margem do Ocidente. São Paulo: Cia. das Letras; Brasília: MinC-Funarte, 1999. p. 237-249.

PENTEADO, Y. M. B. A condição urbana: estudo de dois casos de inserção do índio na vida citadina. 1980. 118 f. Dissertação (Mestrado em Antropologia) - UnB, Brasília, DF, 1980. 
PESSANHA, E. Fronteiras disciplinares e o uso da história oral: por que, de quem, para quem? In: MEIHY, J. C. S. B. (Org.). (Re)introduzindo História Oral no Brasil. São Paulo: Xamã, 1996. p. 71-81.

PORTELLI, A. O massacre de Civitella Val di Chiana (Toscana: 29 de junho de 1944): mito, política, luto e senso comum. In: FERREIRA, M. de M.; AMADO, J. (Org.). Usos e abusos da história oral. 5. ed. Rio de Janeiro: FGV, 2002. p. 103-130.

RICARDO, C. A.; RICARDO, F. (Ed.). Povos indígenas no Brasil 2006/2010. São Paulo: Instituto Socioambiental, $2011.763 \mathrm{p}$.

RIESTER, J. En busca de la loma santa. La Paz; Cochabamba: Los Amigos del Libro, 1976. $376 \mathrm{p}$.

Textos sagrados de los Guaranies en Bolivia: una cacería en el Izozog. Santa Cruz de la Sierra: APCOB, 1994. 257 p.

SANTANA, Á. C. A língua chiquitano no Brasil: aspectos fonéticos, fonológicos e transnacionais. In: SILVA, J. A. F. (Org.). Estudos sobre os Chiquitanos no Brasil e na Bolivia: história, língua, cultura e territorialidade. Goiânia: UCG, 2008. p. 61-96.

SCHWARCZ, L. K. M. História e antropologia: embates em região de fronteira. In: SCHWARCZ, L. K. M.; GOMES, N. L. (Org.). Antropologia e história: debate em região de fronteira. Belo Horizonte: Autêntica, 2000. p. 11-31.

SILVA, J. A. F. Território e fronteiras Brasil-Bolívia no país dos Chiquitanos. Revista do Museu Antropológico da UFG, Goiânia, v. 5/6, n. 1, p. 179-212, jan./dez. 2001/2002.

SILVA, J. A. F.; JOSÉ DA SILVA, G. História indígena, antropologia e fontes orais: questões teóricas e metodológicas no diálogo com o tempo presente. Revista História Oral, Rio de Janeiro, v. 13, n. 1, p. 33-51, jan./jun. 2010.

SILVA, R. H. da. Brasileiros, bolivianos ou indígenas? Construções identitárias dos Camba no Brasil, 2009. 207 f. Tese (Doutorado em Antropologia) - UFF, Niterói, RJ, 2009.

SILVA, S. A. da. Costurando sonhos: trajetória de um grupo de imigrantes bolivianos em São Paulo. São Paulo: Paulinas, 1997.292 p. (Estudos e Debates).

VAINFAS, R. Micro-história: os protagonistas anônimos da história. Rio de Janeiro: Campus, 2002. $163 \mathrm{p}$.

\section{Fontes orais}

OLIVEIRA, M. M. L. A. de; LOPES, B. A. Narrativas. Entrevista concedida a Giovani José da Silva, Corumbá, 23 out. 2008. 
ROCHA, N. Narrativas. Entrevista concedida a Giovani José da Silva, Corumbá, 10-11 abr. 2006 a.

ROCHA, N. Narrativas. Entrevista concedida a Giovani José da Silva, Corumbá, 17 jul. 2006b.

Resumo: $\mathrm{O}$ artigo tem por objetivo apresentar as vivências de uma população indígena localizada atualmente no município de Corumbá, estado de Mato Grosso do Sul, Brasil. Recuperando-se a memória de um ancião Chiquitano, além das de outros indígenas, surgem personagens e tramas que envolveram o processo histórico de migração e marcaram a presença dos Camba-Chiquitano (autodenominação do grupo) na fronteira Brasil-Bolívia. Com essas informações, o objetivo passa a ser a percepção das identidades e práticas culturais elaboradas pelos Kamba a partir da segunda metade do século XX, bem como de quais foram as estratégias adotadas pelo grupo para garantir a sua sobrevivência física e cultural até os dias atuais em uma região transnacional. Nas narrativas orais estão presentes importantes elementos, tais como a memória social, as fronteiras, as culturas de migração e as identidades étnicas e nacionais, analisadas em perspectiva histórica.

Palavras-chave: diversidade étnica, fontes orais, fronteira Brasil-Bolívia, vivências e narrativas, índios Kamba.

\title{
Ethnic diversity and oral sources in borders: Camba-Chiquitano experiences and
} narratives between Brazil and Bolivia

\begin{abstract}
The article aims to present the experiences of an indigenous population currently located in the city of Corumbá, state of Mato Grosso do Sul, Brazil. Retrieving memories of an elder Chiquitano, besides those of other indigenous, characters and plots involved in the historical process of migration and that marked the presence of the Camba-Chiquitano (selfdesignation of the group) in the Brazil-Bolivia border, arise. With such information, the goal becomes the perception of how the Kamba, from the second half of the 20th century, developed identities and cultural practices in order to live and which were the strategies adopted by the group that ensured the physical and cultural survival to the present day in a transnational region. Important elements, such as social memory, borders, cultures of migration, and ethnic and national identities are in these oral narratives, analyzed in a historical perspective.
\end{abstract}

Keywords: ethnic diversity, oral sources, Brazil-Bolivia border, experiences and narratives, Kamba natives.

Recebido em 29/01/2013

Aprovado em 08/06/2013 